Research Article

\title{
Collaborative Evolution Mechanism of PMC Project Organizational Management System from the Perspective of Organizational Conflict
}

\author{
Hongyan Li $\mathbb{D}^{1},{ }^{1}$ Jingchun Feng, ${ }^{1}$ Ke Zhang $\mathbb{D}^{1}{ }^{1}$ Rundong Chen, ${ }^{2}$ Haiyu Feng, ${ }^{3}$ \\ and Tengfei Wang ${ }^{4}$ \\ ${ }^{1}$ Project Management Institute, School of Business, Hohai University, International River Research Center, \\ Nanjing 211100, China \\ ${ }^{2}$ Department of Water Resources, Guangxi Zhuang Autonomous Region, Guangxi, China \\ ${ }^{3}$ Guangxi Zhuang Autonomous Region Water Resources Engineering Construction Management Center, Guangxi, China \\ ${ }^{4}$ China Water Resources Beifang Investigation, Tianjin, China
}

Correspondence should be addressed to Ke Zhang; zhangke@nuaa.edu.cn

Received 26 September 2021; Accepted 19 October 2021; Published 13 November 2021

Academic Editor: Debiao Meng

Copyright (C) 2021 Hongyan Li et al. This is an open access article distributed under the Creative Commons Attribution License, which permits unrestricted use, distribution, and reproduction in any medium, provided the original work is properly cited.

\begin{abstract}
Limited by traditional construction project management ideas and systems, the implementation of the PMC model in China still has serious problems such as opposition and frequent conflicts. How to reveal the causes of organizational conflicts and explore the key mechanism of the implementation of the PMC model from the system perspective are urgent problems to be solved. Based on the idea of engineering system view, this paper abstracts the PMC project participants with self-organizing characteristics of the organizational management system, in which the internal structure is closely related, and defines the connotation of synergy and synergistic evolution of the PMC project organizational management system. Using the Cucker-Smale model to describe the group movement, the hierarchical system and the acceleration efficiency function of the project legal person's free will are constructed, and the structure, movement, and development law of the system itself are emphasized to simulate the ordered evolution trend of PMC project organizational management system and reveal the intrinsic causes of conflicts in PMC project and the key mechanisms of the PMC model application. The results show that first, the intensity of information communication between PMC subjects has a significant positive contribution to the orderliness of the organizational management system; second, too much acceleration of the project legal person's free will causes group chaos in the system, while too little slows down the group stabilization time, which has a negative impact on cost and schedule; third, the more the organizational structure of PMC contractors tends to the whole-process integrated control, the more it can drive the group to gather in an orderly manner and form a synergistic control mode combining self-organization and other organizations; and fourth, the implementation of the PMC model should focus on eliminating the traditional institutional and conceptual barriers, forming a project management model with integrated control of the whole process of the PMC project contractor and effective macro supervision of the project legal person. The research results of this paper revealed the intrinsic causes of conflicts in PMC projects and the key mechanisms of PMC model application; it can help solve the confrontational situation of PMC project participants, promote the development of the PMC model, and give full play to the investment benefits.
\end{abstract}

\section{Introduction}

China's construction industry is a pillar industry of the national economy and has driven a large number of related industries, making important contributions to economic and social development, urban and rural construction, and improvement of people's livelihood. About 3,424.7 billion yuan of investment in fixed assets for transportation and 770 billion yuan of investment in water conservancy were completed in 2020, and the large-scale, modern 
infrastructure, industrial, and civil building construction have demonstrated the advanced and reliable nature of China's engineering technology, technical standards, and work methods. The "One Belt and One Road" initiative has been proposed for more than seven years and has won wide recognition from the international community. By the end of January 2021, China has signed 205 cooperation documents with 140 countries and 31 international organizations for the co-construction of "One Belt and One Road." China's construction industry has made remarkable achievements in the field of international engineering construction, but there is still a big gap compared with the construction industry of advanced industrialized countries; the construction labor productivity is only about two-thirds of that of developed countries; the construction industry is still big but not strong; the organization of engineering construction is backward; the level of architectural design needs to be improved; there are more market violations; the core competitiveness of enterprises is not strong; and other problems are more prominent. Under the influence of Chinese traditional thinking and traditional system, the organization and management of construction projects are still limited to the scope of project contracting business and split organization model [1]. In the traditional management model, the participants who are responsible for decisionmaking, construction, and operation services [2] provide services on behalf of the interests of the project legal person in the corresponding phase. Medium and large construction projects span civil, electrical, planning, environmental, and other functional departments to work together, and the connection between the participants is extensive and close and affects each other. As the project progresses, the relationship between participants changes dynamically, resulting in greater complexity of project organization and management. In addition, the different expertise and experience of each participant also increase the complexity of project coordination, which is more likely to cause problems such as confrontation and conflict among project participants. The high-quality development of the construction industry urgently needs to establish real good cooperation between all participants and improve the efficiency of organizational implementation [3]. Obviously, the traditional project management system, management style, and philosophy in China cannot meet to the needs of modern medium and large-scale project management.

Engineering practice cases showed that the PMC model (project management contracting model) has the advantages of design optimization, integrated management, risk redistribution, and cost-saving compared with traditional DB and DBB models [4]. PMC model is an organizational model to meet the market demand and implement the whole process of engineering consulting in the project decisionmaking and construction implementation stages [5], mainly to provide high-quality intellectual and technical services for construction activities. PMC model refers to the engineering project management enterprise (PMC contractor), in accordance with the contract, preparing a feasibility study, feasibility analysis, and project planning for the owner at the decision-making stage; providing bidding agent, design management, procurement management, construction management, and commissioning (completion and acceptance) services for the owner at the implementation stage; and carrying out quality, safety, progress, cost, contract, and information management and control of the project on behalf of the owner. The PMC contractor shall generally bear certain management risks and economic responsibilities in accordance with the contract. Its essence is to provide highquality whole-process intellectual and technical services for the project legal person. PMC project refers to the construction project that adopts the PMC model for the whole process integrated and professional organization and management. In February 2017, the Ministry of Housing and Construction issued document 19, the first time mentioned "whole process engineering consulting" concept, and in 2019, the National Development and Reform Commission and the Ministry of Housing and Urban-Rural Development jointly issued "Guidance on Promoting the Development of Full-Process Engineering Consulting Services" (Development and Reform Investment Regulations (2019) No. 515), which pointed out the urgent need to innovate the organization and implementation of consulting services and vigorously develop full-process engineering consulting service model oriented by market demand and meeting the diversified needs of commissioners. A series of construction project management-related regulations and practical applications have accumulated rich experience in promoting professional management of large-scale engineering project management [6]. PMC model is widely used in large-scale international project construction, for example, the South China Sea ethylene project undertaken by SINOPEC Engineering and Construction Corporation, the Bangladeshi Chittagong-Dhaka refined oil Pipeline Project undertaken by Langfang CNPC Langwei Engineering Project Management, the China-Myanmar Oil and Gas Pipeline Project undertaken by CNPC Pipeline Engineering Co., and so on [7]. The PMC model has become one of the important project management models in oil, transportation, water conservancy, and other industries [8].

The current research on the PMC model focuses on the theoretical definition and scope of the PMC model, risk study of the PMC model [9], schedule and cost control study [10], application practice study, and comparison study with other models [11]. Both domestic and foreign scholars have focused on the operational aspects of the PMC model, discussing how the PMC contractor conducts planning, design, and management scope of the PMC contractor, the risk of lump-sum contracts under unclear conditions, and institutional barriers to the promotion of the model. The research results of the PMC model have provided reference ideas for the professional management of construction projects [12], as an extension of the owner; the PMC contractor manages the whole process of project construction to achieve safe, high quality, low cost, and on-schedule completion of the project in accordance with the predetermined objectives and to optimize the technical and economic indicators over the life of the project. In the traditional project management model, the decision-making, implementation, and operation phases are independent, and the professional 
engineers who undertake the tasks of different phases provide consulting services for the owner in the corresponding phases, and the antagonism between the owner and the contractor is deep-rooted. Field research on PMC projects is implemented in China, due to the lack of systematic operation norms and references, and the influence of traditional construction project management ideas and systems; conflicts between PMC contractor and owner, supervisor, designer, and constructors are frequent in the project implementation Owners and PMC contractors do not trust each other; supervisor and designer and PMC contractor constrain each other in the implementation; and constructors do not recognize PMC contractor's management. The PMC contractor is in an awkward position, and it is difficult to coordinate the relationship between all parties, and the confrontation and contradiction between the parties is intensifying as the project progresses. This is extremely mismatched with the current development demand of the construction industry; it is difficult to meet the needs of a high-quality development strategy [13]. It is urgent to introduce the system thought to explore the overall and integrated way of organization and coordination [14]. In view of this, the paper abstracts the PMC participants into an organizational management system with self-organizational characteristics from the perspective of system theory, using the Cucker-Smale group movement model, emphasizing the structure, movement, and development law of the system itself, highlighting the integrity and dynamics of the system operation, simulating the PMC participants of exchanging information and interacting with each other within the system, and identifying the underlying causes of organizational conflict among PMC project participants in the Chinese context, to facilitate in-depth study of the management mechanism of PMC projects. The paper explores the evolutionary mechanism and evolutionary dynamics of synergy formation in PMC project organizational management systems so that the PMC model can get rid of management dilemmas such as antagonistic participants, frequent conflicts, and low organizational efficiency; realize efficient collaboration among the participants, in order to promote the development of the PMC model in the field of Chinese construction project; and provide theoretical references for the revolution of the project management model.

\section{Literature Review}

The existing collaborative studies of construction projects were mainly based on the relationship between the participants to construct the relationship network [15]. Dogan et al. used SNA to construct an e-mail communication network between the participants of a large airport construction project and calculated closeness centrality to evaluate project coordination performance [16]. Zhao et al. constructed an organizational network between participants based on e-mail log data from a $\$ 20$ million AEC project to identify inconsistencies between organizational and collaborative networks, with the aim of analyzing the patterns of collaboration achieved by the project [17]. Conflict within the organization is one of the main factors affecting project synergy due to the diversity of interests and goals among project participants [18]. Conflict in the project construction process is dominated by interorganizational conflict, which refers to the interactive process in which actors show different interests, views, and preferences [19]. With the development of the economy, the increasing scale and technical complexity of engineering projects, the emergence of various new transaction models and project management models, the organizational conflicts of construction projects have increased dramatically. In addition to multi-cultural, multi-disciplinary, and different objectives that lead to organizational conflicts, the technical capacity or coordination ability, experience, and economic capacity of the professional team also lead to organizational conflicts [20]. In owner management, untimely owner decisions, excessive supervision, poor coordination, lack of management ability, failure to provide information or sites in a timely manner, and failure to follow procedures for handling unreasonable contractor claims can lead to conflicts [21]. This requires the project manager to have the ability to coordinate conflicts between the participants and make the project organization synergistic [22]. Most conflicts originate early in the project lifecycle, and it is important to take measures to mitigate them early on [23]. Jin et al. proposed conflict resolution strategies for the planning, construction, and handover phases by building a dynamic social network model among project participants [18]. Wang et al. discussed the causes and solutions of conflict in the construction project through multiple case studies and proposed the following six resolution strategies: (1) prevention, (2) compromising, (3) mediation, (4) resolving, (5) avoidance, and (6) smoothing [24]. Postevaluation of conflict management is also an important part, assessing the quality of conflict management in five dimensions: satisfactory resolution outcome, comprehensive resolution process, conflict prevention, perception of fairness, and postconflict effects [25]. The construction field has conducted relatively in-depth research from both the analysis of the root factors of conflict and conflict management strategies, with a focus on the study of the conflict between owners and contractors.

Construction projects are open organizational systems involving many important stakeholders, while medium and large construction projects have more complex social, cultural, and legal contexts so more complex conflict factors within the organization [26]. Most of the existing studies on conflict management are based on the local perspective of some participants or in phases, the studies on project organization issues and organizational behavior are still scattered, and there is a lack of systematic studies on conflict management in medium- and large-scale projects [27]. Systems theory stems from the investigation of natural phenomena; in 1978, Qian et al. published the article "Technology of Organizational Management-Systems Engineering," which opened a new era of systems engineering research in China [28]. In this article, a system is defined as an organic whole with specific functions, which consists of several components that interact and depend on each other, and any engineering project is a social system with continuous dynamic evolution composed of subsystems that 
interact and work together. Yin et al. from the perspective of engineering ontology and engineering system view proposed to look at engineering from the perspective of human survival and development, not only recognize various elements of engineering composition but also see engineering as a system, and recognize, analyze and grasp engineering from the system viewpoint [29]. The study of construction project organizational behavior requires a broader systematic perspective. As temporary organizations, construction project organizations can be viewed as complex adaptive organizations, where the behaviors of participants at all levels interact and change dynamically [30]. Principled negotiation and joint cooperative action among participants within the project organizational system can play an important role in mediating conflicts, and interorganizational trust has direct and indirect positive impacts on improving cost performance [31].

Based on the engineering system theory, the project organizational management system is a group composed of many independent participants who depend on each other [32], which belongs to an open organizational system, and the relationship between the participants constitutes the organizational structure. In this paper, the definition of synergistic project organizational management system is as follows: under the disturbance of the external environment, the internal participants of the system have a stable connection, forming an orderly structure of internal and external energy, material and information exchange, and continuously maintaining the dynamic stability of the system structure. Definition of PMC project organizational management system synergy evolution is an organizational process in which the interactions between project participants move toward orderly and dynamic stability, forming a life-like group that combines self-organization and other organizations, in which the participants under the leadership of the commander adapt to other participants in the system by changing their rules, with the ability of self-development, self-improvement, and spontaneous synergy so that the overall system exhibits dynamic synergy. The research results help PMC projects mitigate organizational conflicts and synergize the strengths of all parties involved, provide theoretical references for innovative project management models and the implementation of specialized PMC models, open up paths for achieving integrated and specialized management of the whole process in the field of construction, and significantly improve management effectiveness and construction management levels.

\section{Methodology}

It is observed that self-driven particles such as flocks of birds, fish, and sheep have self-organized group behavior and can transition from disorder to orderly motion using local information and simple rules. Group behavior is characterized by certain macroscopically ordered behaviors of individuals in a group through interactions, with "order" usually referring to the same movement patterns [33]. In 1995, Vicsek et al. proposed the first numerical model to describe animal group behavior, and Jadbabaie et al. proved the correctness of the above numerical model from the mathematical point of view $[34,35]$. Based on the above research, Cucker and Smale studied the formation mechanism of orderliness and proposed the Cucker-Smale model to describe interactions between particles [36, 37]. The Cucker-Smale model analyzes the formation mechanism of group coherence by describing the position and velocity of individuals and interindividual interactions during group motion and establishing a mathematical model; the authors also demonstrate the validity of the model by using the formation of a common language in primitive societies and the emergence of the vowel system as examples.

Each individual in the Cucker-Smale model adjusts its velocity by summing the weighted average of the difference between its own velocity and that of other individuals. Given $k$ particles in $d$-dimensional Euclidean space, $\left(x_{i}, v_{i}\right)$ denotes the position and velocity of the $i$-th particle $(i=1,2, \cdots, k)$, and the velocity and position updates of these $k$ particles obey following the system of the below equation:

$$
\begin{aligned}
& x_{i}(t+\Delta t)=x_{i}(t)+\Delta t v_{i}(t), \\
& v_{i}(t+\Delta t)=v_{i}(t)+\Delta t \sum_{j=1}^{k} a_{i j}(x(t))\left(v_{j}(t)-v_{i}(t)\right),
\end{aligned}
$$

where $x_{i}(t)$ and $v_{i}(t) \in \in \mathbb{R}^{3}$ denote the position and velocity of individual $i$ at time $t$, respectively, and $\Delta t$ is the time step.

$a_{i j}(x(t))$ quantifies the strength of interactions between individuals, and the strength of interactions between individuals is a smooth decreasing function of relative distance, as shown in equation (2). As can be seen from $a_{i j}(x(t))$, the model is a symmetric interaction model, that is, the information transfer is bidirectional, and the interactions between subjects diminish as the relative distance increases, but the interactions are always strong or weak.

$$
a_{i j}(x(t))=\frac{H}{\left(\sigma^{2}+\left\|x_{i}(t)-x_{j}(t)\right\|^{2}\right)^{\beta}}
$$

where $H>0, \alpha>0$, and $\beta \geq 0$ are the system parameters and $\beta$ is the decay rate.

Definition 1.1. The solution $(x, v)$ of system (1) with asymptotic group effect means that

(1) Relative velocity tends to be 0 , that is, $\lim _{t \rightarrow+\infty}=\left|v_{i}-v_{j}\right|=0,1 \leq i, j \leq k$

(2) Relative displacement aggregation, that is, $\sup _{0 \leq t<\infty}\left|x_{i}(t)-x_{j}(t)\right|<+\infty, 1 \leq i, j \leq k$

Shen proved the correctness of the Cucker-Smale model using induction and obtained convergence results similar to the original model [38]. Cucker and Dong further explored the Cucker-Smale model with a hierarchical structure using a subsystem induction approach and using a flock of birds perched on a branch and suddenly disturbed by a predator as an empirical case [39]. Subsequent researchers have proposed various improvements to the Cucker-Smale model to suit different application scenarios and have also validated 
the validity of the model from different perspectives. Cucker et al. and Dong et al. studied improved models affected by noise and time delay, giving threshold conditions for the occurrence of group behavior [40-42]. Cucker and Markou I et al. improved the model for collision avoidance by adding repulsive forces [43-45]. Cucker and Dong studied the Cucker-Smale model with the introduction of hierarchy and topologically acting neighborhoods, giving conditions for the occurrence of cluster clustering $[46,47]$.

Cluster dynamics models were originally used to simulate the group motion of animal groups in nature, and in recent years, such models have also been mostly used to study the control mechanisms of the asymptotic behavior in multi-intelligent body systems [48]. Examples including aircraft formations [49], robotic mass movements, and engineering science research [50] provide basic coordination and consistency algorithms for mobile autonomous individual systems. The famous Chinese economist Cheng pointed out that the most essential characteristic of a complex system is that its components have some degree of intelligence, that is, the ability to understand their environment, anticipate its changes, and act on predetermined goals, which is intrinsically responsible for biological evolution, technological innovation, economic development, and social progress [51]. The current research on the coordination of construction project participants is mostly based on SNA. SNA portrays the intersubject relationship through the network structure model and conducts a static quantitative evaluation of the density, centrality, and other indicators, but the organizational network structure changes dynamically as the project advances, and the static evaluation of SNA can hardly reflect the dynamic nature. The PMC project organizational management system is composed of several participants, who have independent interest goals and act according to the predetermined goals. As the project progresses, the interaction between the participants will prompt them to continuously receive information [52], summarize the experience, adjust action rules, improve their own adaptability, and make the system evolution more and more complex. In summary, this research introduces the Cucker-Smale cluster dynamics model, considers the characteristics of PMC project organizational structure, constructs the effectiveness function of the interaction between participants in the PMC project organizational management system, simulates the evolution process of the interaction of participants, identifies the causes of conflicts in PMC project organizational management systems, and explores the mechanisms and paths to achieve synergy and consistency. The research framework is shown in Figure 1.

\section{Collaborative Evolutionary Model of PMC Project Organizational Management System}

Referring to the research results of the Cucker-Smale model, a hierarchical PMC project organizational management subsystem with $k+1$ project participants is considered, as shown in Figure 2, containing the project legal person, the
PMC contractor, the design unit, the supervision unit, and the subcontractors. Project legal person refers to the highest authority group or organization that has civil rights and civil capacity, enjoys civil rights, undertakes civil obligations independently according to law, and is engaged in project management for the purpose of construction projects, and the project legal person is in a central position during the implementation stage of construction projects and is responsible for the whole process of project implementation. Therefore, in the project organizational management system, the project legal person is the general leader of the group and has the acceleration of free will. In the process of project implementation, the acceleration of free will reflects the willingness of the project legal person to lead and drive the group. The model sets the project legal person corporation code to 0 and the PMC contractor code to 1 .

In Figure 2, if the adjacency matrix $A=\left(a_{i j}\right)$ satisfies:

(1) $a_{i j} \neq 0$, then it means $j<i$

(2) Define $\zeta(i)=\left\{j: a_{i j} \neq 0\right\}$ as the set of leaders of behavioral agent $i$, for any $i>0, \zeta(i) \neq \varnothing$

The rules of movement for the $2 \mathrm{nd}$, 3rd up to the $k$-th behavioral agent are shown in the system of the following equation:

$$
\begin{aligned}
& x_{i}(t+1)=x_{i}(t)+\Delta t v_{i}(t), \\
& v_{i}(t+1)=v_{i}(t)+\sum_{j \in \zeta(i)} a_{i j}(t)\left(v_{j}(t)-v_{i}(t)\right),
\end{aligned}
$$

where $i=2, \ldots, k ; x_{i}(t), v_{i}(t) \in \mathbb{R}^{3}$ denote the position and velocity of behavioral agent $i$ at time $t$, respectively; and $\Delta t$ is the time step. The velocity update rule of the behavioral agent is to adjust its own acceleration by receiving the velocity difference information with individuals in the leader set to achieve velocity matching.

$a_{i j}$ is a function of the intensity of the interaction between the participants, as in the set of equations (4), which is the weight function of the individual in adjusting its own speed, indicating the strength of the information received by the individual to change its speed; it also reflects the efficiency of information delivery and communication. Unlike the original Cucker-Smale model, $a_{i j}(t)$ is a one-way asymmetric decreasing function where behavioral agent $i$ is influenced only by the individuals within its leadership $\operatorname{set} \zeta(i)$.

$$
a_{i j}(t)=\frac{1}{\left(1+\left\|x_{i}(t)-x_{j}(t)\right\|^{2}\right)^{\beta}},
$$

where $\beta \geq 0$ is a system parameter indicating the decay rate.

Each participant updates their position and speed according to the difference in action with other individuals within the leadership set, and the action update rule for the total leadership project corporation 0 is as in the following equation:

$$
\begin{gathered}
x_{0}(t+1)=x_{0}(t)+\Delta t v_{0}(t) \\
v_{0}(t+1)=v_{0}(t)+\Delta t f(t)
\end{gathered}
$$




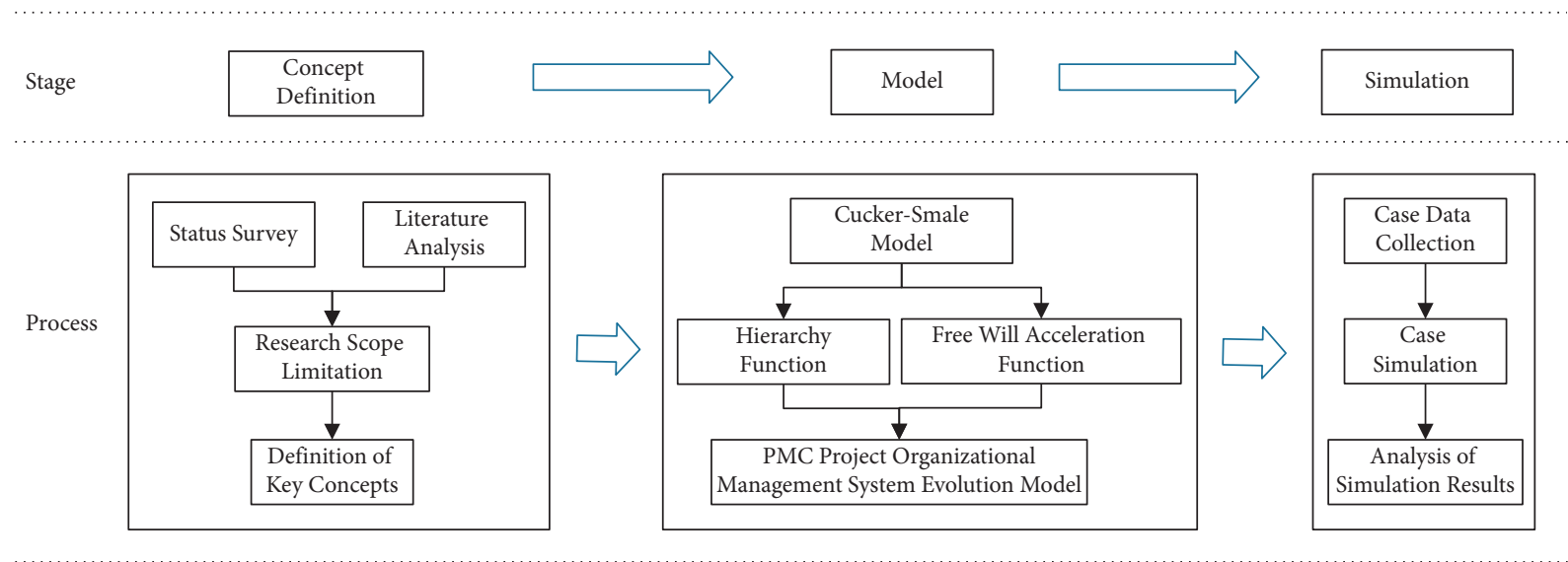

FIgURE 1: Research framework and process.

The action update rule of PMC contractor 1 is shown in the system of the following equations:

$$
\begin{aligned}
& x_{1}(t+1)=x_{1}(t)+\Delta t v_{1}(t), \\
& v_{1}(t+1)=v_{1}(t)+\sum_{j \in \zeta(1)} a_{1 j}(t)\left(v_{j}(t)-v_{1}(t)\right),
\end{aligned}
$$

where $f(t)$ is the free will acceleration of the project legal person, considering the actual change of the project legal person's mentality; the project legal person is more anxious to achieve the goal when the project is first started; and the anxious mentality of the project legal person decreases as the project progresses and project goals are gradually achieved. Therefore, it is assumed that the free will acceleration of the project legal person is a decaying process, reflecting the degree of control and intervention they have over the project. The greater the acceleration of free will, the greater the tendency toward a command leadership style, that is, the greater the control of the project owner over the execution of the project and the demand for immediate compliance by the other participants. The decaying process of the free will acceleration satisfies the following process:

$$
\|f(t)\|=\mathrm{O}\left((1+t)^{-\delta}\right), \quad \delta>k
$$

$\mathrm{O}\left((1+t)^{-\delta}\right)$ is an infinitesimal function of the same order as $(1+t)^{-\delta}$, that is, there exists a nonzero constant such that $\lim _{t \rightarrow \infty} \mathrm{O}\left((1+t)^{-\delta}\right) /(1+t)^{-\delta}=c$.

Unlike the EPC model [53], the PMC contractor, as an extension of the project legal person in project management, is designed to make up for the lack of management capacity of the project legal person, fully reflecting the interests of the project legal person, whose profit comes from the management fee, and can eliminate the shortcomings of the project legal person's inexperience and inappropriate management in the coordination of management. Therefore, PMC contractor is more influenced by the free will acceleration of the project legal person than the same level of participants, and the intensity of the free will acceleration of the project legal person on PMC contractor is set twice as much as that of the same level of agents after interviews and research with PMC project managers and experts in the field of project management.
Groups have group effect, that is, they form synergies and satisfy the following conditions:

(1) The relative speed of all participants is consistent, $\lim _{t \rightarrow \infty}\left|v_{i}-v_{j}\right|=0,0 \leq i, j \leq k$

(2) All participants are bounded by their relative positions of aggregation, $\sup _{0 \leq t<+\infty}\left|x_{i}(t)-x_{j}(t)\right|<+\infty$, $0 \leq i, j \leq k$

\section{Case Study}

5.1. Project Brief. PMC project of Guangxi Baise reservoir irrigation area was selected for simulation analysis (hereinafter referred to as $M$ Project). M Project reservoir irrigation district project is located in the valley of the Right River in Baise City, involving a total of 12 towns in Baise City, which is one of the " 172 " major water conservation and water supply water conservancy projects determined by the State Council; the project is a large (2) type II irrigation district in general, with an investment of 414.471 million yuan and total construction period of 48 months. The project consists of two parts: reservoir diversion project and right river water lifting project, with irrigation and water supply as the main tasks, irrigating an area of 592,000 mu; the water transmission mains are divided into five pipes, including the main pipe, south main pipe, north main pipe, Lin Feng main pipe, and Baoqun main pipe.

The M Project involves many participants, a wide geographical distribution, an organizational management system across a variety of technical specialties, and cultural differences; it is difficult for the traditional project organization fragmented management approach to meet the project construction, project contracting using the PMC model. This is the first time that the PMC model is adopted for a large water conservancy irrigation project in China and the first water conservancy project in Guangxi Zhuang Autonomous Region to adopt the PMC model. The organizational structure of the organizational management system is shown in Figure 3, where the project legal person is contracted in parallel for supervision, design, tunnel construction, and PMC contracting. The PMC contractor manages the whole process of construction preparation: 


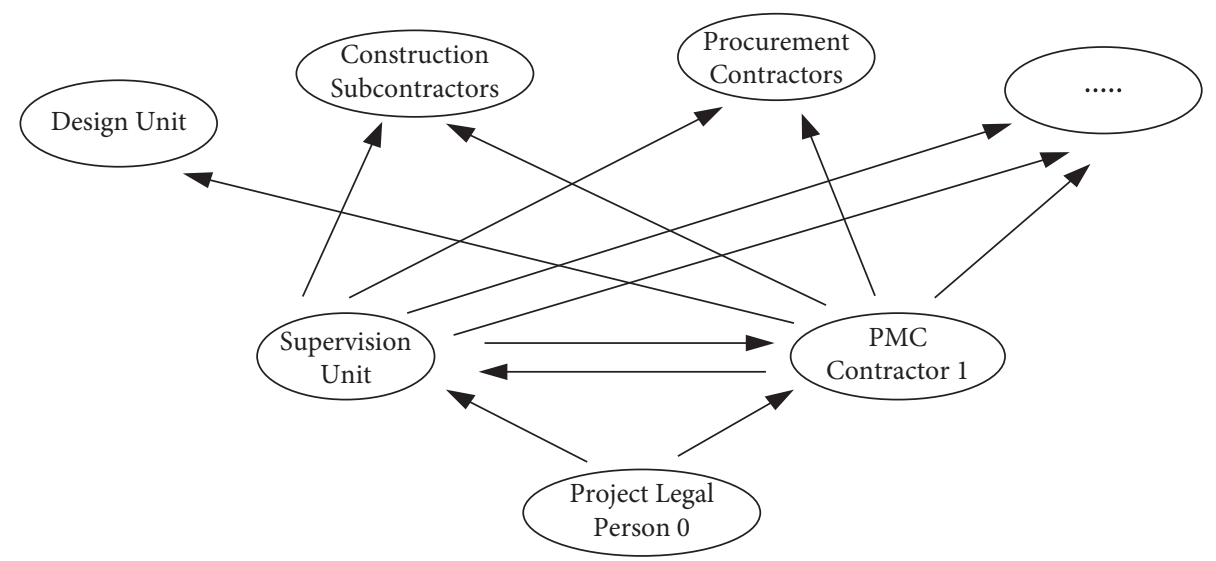

Figure 2: Hierarchy diagram of PMC project organizational management system.

procurement of project materials and equipment, construction of main works, temporary works, soil and water conservation works, environmental protection works, acceptance of project completion, monitoring (all safety, environmental and soil and water conservation monitoring), project insurance, commissioning, and project handover in accordance with the scale, function, and technical standards defined in the approved Preliminary Design Report of $\mathrm{M}$ Project. During the construction period, the contractor controls and manages the project schedule, quality, safety, cost, contracts, information, and files and prepares the completion information. contractor is also responsible for coordinating supervision and design, playing the role of "control, guidance, coordination, and service." As shown in Figure 4, the PMC contractor is fully responsible for the construction management and implementation of the main project and bears the corresponding management risks and economic responsibilities according to the contract.

The conflicts between the participants in the implementation of this project are mainly manifested in the following aspects: (1) conflicts between PMC contractor and project legal person. The project legal person belongs to the command leadership style and has less experience in largescale project management, the comprehensive strength of the PMC contractor is much higher than the project legal person, which leads to the project legal person's concern of not being able to control the moral risk of the PMC contractor. So the project legal person does not trust the PMC contractor and has greater actual control over the project, regularly bypassing the $\mathrm{PMC}$ contractor to organize the work of other participating entities and carry out engineering inspection independently, which makes the PMC contractor's position awkward. (2) Conflicts between the PMC contractor and the design and supervision parties. According to the contract, the PMC contractor is responsible for coordinating and managing the supervision side and the design side, but in the actual implementation of the organizational structure (Figure 3), the supervision and design are awarded by the project legal person in parallel, the supervision side is responsible for supervising and managing the PMC contractor, and it is difficult for the PMC contractor to coordinate the work of the supervision side and the design side, so the positioning and management scope between the three is blurred. (3) Conflicts between PMC contractor and construction parties. Because the project legal person does not support the work of the PMC contractor so that the PMC contractor is in an awkward position between the project legal person and other construction sides, resulting in the construction sides do not recognize the management of the PMC contractor and autonomy and do not listen to its views, resulting in poor management of subcontracting teams; the project has more quality problems and rework.

5.2. Case Simulation Analysis. Based on Figures 3 and 4, the management level diagram of the participants in the $M$ project organizational management system is summarized as shown in Figure 5. PMC contractor is entrusted by the project legal person to undertake the project construction management; implement the whole process management of project quality, project schedule, capital management, and production safety; and accept the supervision of higher authorities and project authorities. The project legal person is the supervision and inspection layer; the general project management contractor is the management layer; the design and supervision unit are the control layer; the construction unit and suppliers are the construction guarantee layer; and the participants are numbered.

The initial conditions of the simulation are set as follows: the number of participants is 23 ; the initial velocity of each individual is in the range of $0-10 \mathrm{~m} / \mathrm{s}$; the simulation duration is 100 ; the time step is $0.1 ; \beta=0.4$; and in order to avoid the effect of random initial distribution on the results, each simulation is repeated 100 times with random values to take the average value.

In the hierarchical diagram of individual interactions in the M Project organizational management system, each behavioral agent is influenced by the higher level of leadership, and the subcontractors and suppliers at the construction assurance level all influence each other considering the characteristics of the process crossover in engineering construction. The velocity and position trajectory evolution of the participants is shown in Figure 6, and the simulation 


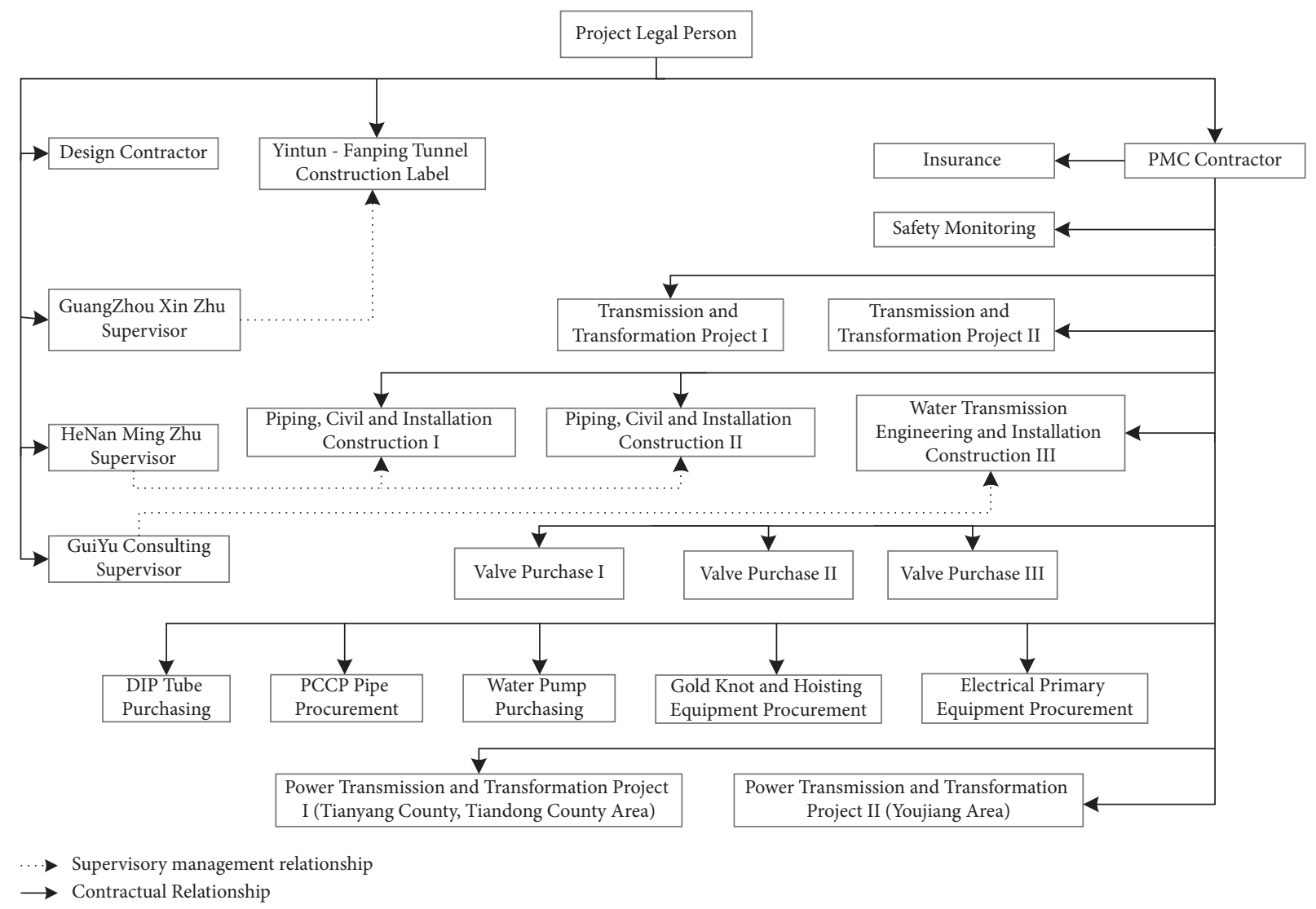

Figure 3: M project organization chart.

results show that there is a lack of synergy between the participants, and they cannot reach a consistent state. The position curve is more divergent; the speed matching curve in the process of movement appears obvious fluctuations; and the oscillation amplitude is larger because at the beginning of the group movement, the individuals are influenced by each other to decelerate first, making the speed gap increase, and then decrease due to the role of speed matching, and the development tends to be stable, but it cannot reach the group effect, that is, it is difficult for the participants of the project organizational management system to cooperate. The simulation results are consistent with the actual project implementation status.

The individual position trajectory curve in Figure 7 shows that the group is severely divided within the group, the organizational goals of each agent are severely divergent, and the personnel of different professions and organizations cannot coalesce in one organization to work together. Individuals only focus on their own interests, ignoring the sustainable development needs of the project, resulting in a discrete organizational management system, and the inconsistency of organizational goals will cause agents to form a situation of mutual constraints, low efficiency, and consuming a lot of costs, time, and energy to deal with work interface conflicts [54]. The individual velocity trajectory curve in Figure 6 cannot converge; there are complex connections within the organizational management system; and the velocity update of the agents depends on information interaction to a great extent. Most parts of the $M$ Project are managed by manual engineering information, and information communication is mostly based on paper media, lacking effective information exchange rules and information integration platforms [55]. There are information silos and information fault, which leads to inconsistent individual behavior [56], such as the lack of in-depth understanding of the requirements of the project legal person and the failure to accurately grasp the implementation plan, which increases the conflicts within the organizational management system, resulting in the project participants pursued by each subject differ greatly. Gradually reducing the decay rate $\beta(\beta=0.3 ; 0.2 ; 0.1)$ of the mutual influence strength function $a_{i j}$ between agents and strengthening the strength of communication between individuals helps the group converge, but the result still cannot reach synergy, as shown in Figure 6.

The overall leader project legal person 0 has free will acceleration $f(t)$. In $M$ Project, the project organization is complex, and the investment scale is large. The project legal person still wants to strengthen its own management and control power over the project under the PMC model due to the traditional construction ideology, so bypassing the PMC contractor to undertake many complicated and detailed management work and responsibilities, it did not reduce its own management pressure by adopting PMC model. But the project legal person does not have the management ability and experience that is compatible with this project; the free 


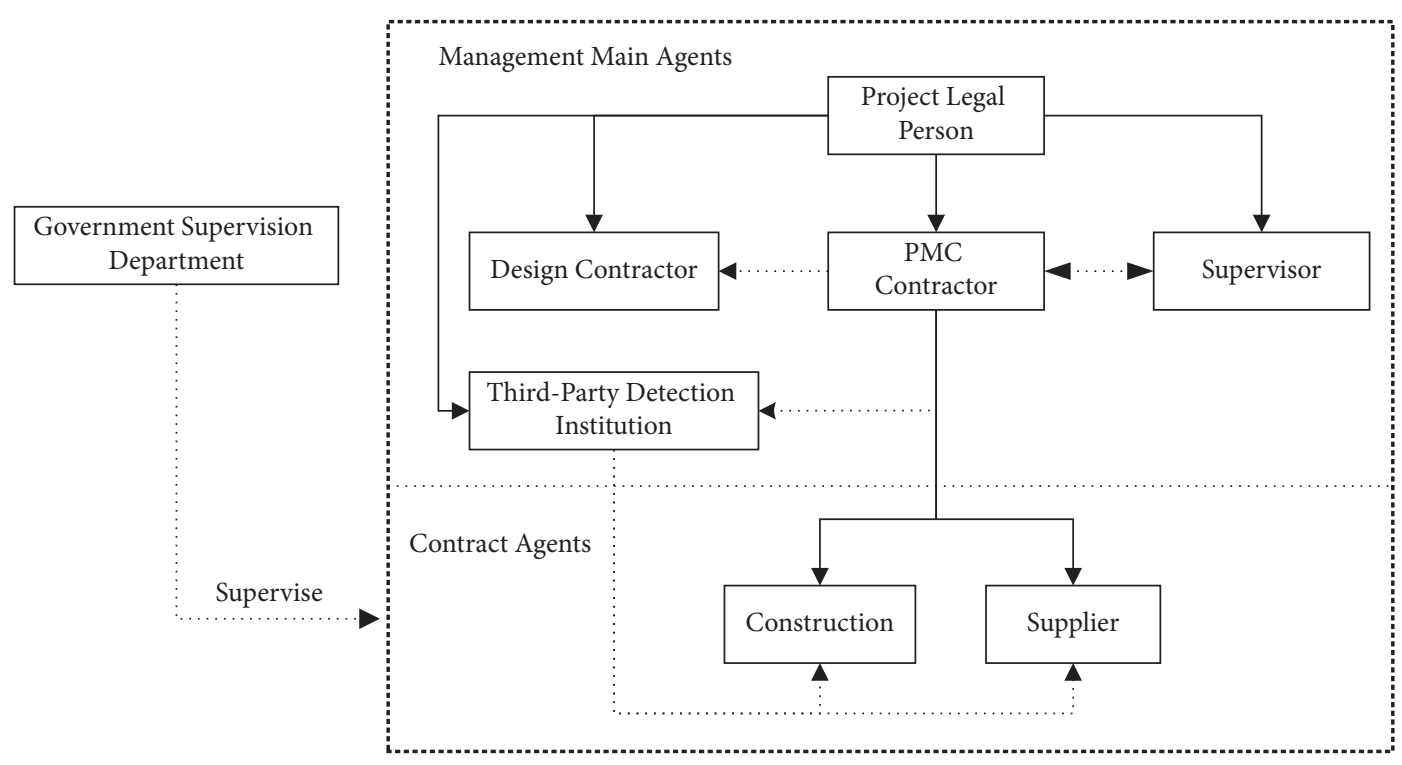

Figure 4: Project management model.

will affects the construction process too much, which makes the management interface blurred and increases the conflicts of the organizational management system [57]. And the project legal person belongs to the command leadership; free will acceleration is larger; coordination of problem-solving is more difficult. Adjusting the size of $r$ in the free will acceleration of the project legal person, the simulation results are shown in Figure 8, and $\delta$ increases in (a), (b), and (c) in order. It can be seen that the larger the value of $f(t)$ taken, that is, the larger the free will acceleration of the total leader, the weaker the attraction between individuals within the group, and the more chaotic the group order of the organizational management subsystem, the more obvious the phenomenon of subgrouping appears in Figure 8(a), and it is more difficult to realize the group effect.

The existing organizational structure of the M Project is fragmented, and the PMC contractor is contracted to coordinate the supervision and design and take the overall responsibility, but in the actual organizational structure, the supervision and design are awarded by the project legal person in parallel, direct management of supervision and design by the project legal person. The PMC contractor has no management authority over the designer and the supervisor, so the designer and the supervisor restrict the professional management of the PMC contractor, which causes many obstacles to the design optimization of the PMC contractor and the control of construction sides. In addition, the project legal person has greater control over the project implementation, and the traditional engineering construction management model of the project under the PMC model is still serious; there are problems of fragmentation and disconnection between all-round management subjects, and the project implementation cannot get rid of the defects of the traditional management model of fragmentation. To adjust the hierarchical structure of the $\mathrm{M}$ Project organizational management system, incorporate supervision, design party, and tunnel construction into PMC management, as shown in
Figure 8, we increase the PMC contractor's control over project management and give full play to its management advantages to fully manage the project construction; the project legal person mainly assumes the responsibility of macro supervision. The simulation results shown in Figure 9 can make the group synergy consistent.

The initial conditions remain unchanged, and the simulation results of the hierarchical structure of Figure 10 are shown in Figures 9(a) and 9(b), where the group velocity tends to be consistent and the individual position curves are consistently bounded, forming a group effect, that is, reaching synergy within the system, but the curve oscillation is still large. Decreasing the decay rate $r$ and strengthening the strength of the interaction between the agents, the amplitude of the oscillation is significantly reduced, and the time for the group to converge is shortened, as shown in Figures 9(c) and 9(d). Continuing to reduce the free will acceleration of the project legal person, as the free will acceleration tends to be 0 , the oscillation gradually decreases, and the group velocity curve smoothly tends to be synergistic. The smaller the fluctuation amplitude of the velocity trajectory curve is, the more easily the velocity among individuals within the group achieves consistent, the more smooth the position trajectory change is, and the position trajectory change becomes consistent with a boundary, as shown in Figures 9(e) and 9(f). However, compared to Figures 9(c) and 9 (d), the continuous reduction of the project legal person's free will acceleration in Figure 9(c) helps the group converge more gently toward synergy, but beyond a certain small range, it makes the group stabilization time slow down, and the group stabilization time in the project process has an important impact on the cost and schedule of the project [58].

\section{Discussion}

Participants adjust their own speed according to the speed difference information received from other individuals, reduce the decay rate of the interaction weight function between 

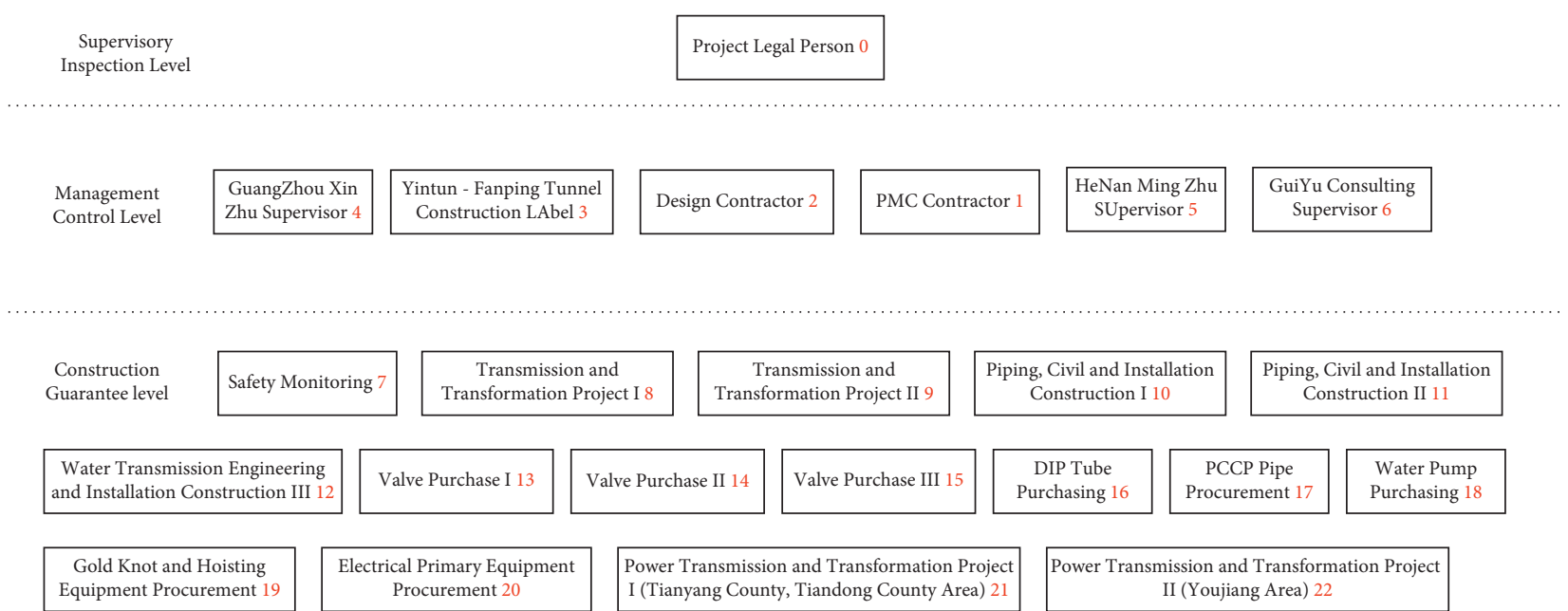

FIGURE 5: M project organizational management system hierarchy.

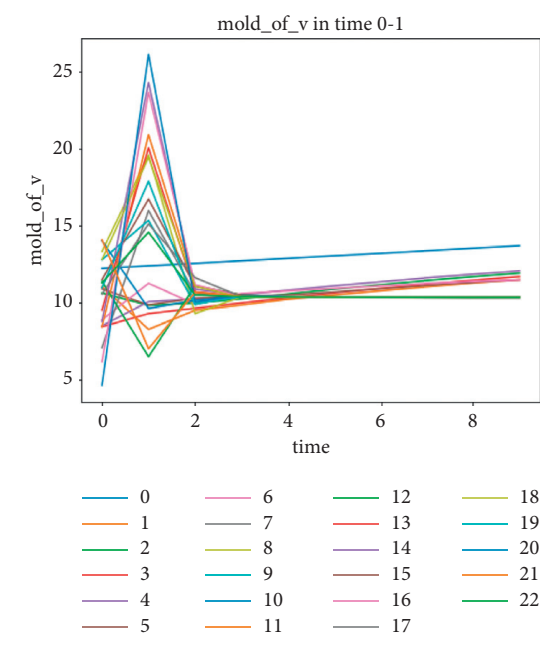

(a)
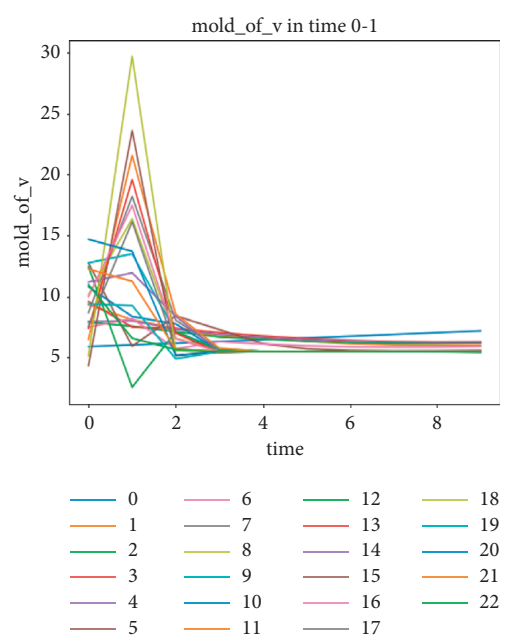

(b)

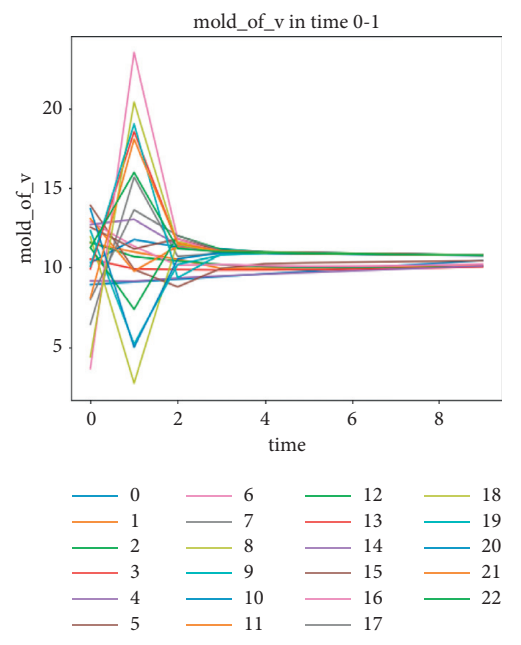

(c)

Figure 6: Velocity evolution curve: (a) $\beta=0.3$, (b) $\beta=0.2$, and (c) $\beta=0.1$.

individuals in the organizational management system, and strengthen the interconnection, that is, increasing the efficiency of effective communication and information sharing between individuals and making the group tend to evolve in the direction of synergy. Regarding project construction from survey, design, construction, completion, and acceptance to operation, as the project progress information accumulates and is passed to the next stage, the participants involve many professions and departments, consuming a long time cycle and spanning a wide geographical area. Due to the limitations of the traditional information management and communication methods, the information transmission process may result in distortion, delay, and failure, which seriously reduces the level of group decision-making. Therefore, it is crucial for the project to achieve information sharing and effective communication in all phases of construction, and the key lies in the development and use of modern information technologies and resources such as building information model (BIM), big data, internet of things, and so on to build a whole life cycle information management system and improve the level of information management and application [59]. It provides a guarantee for participants to make full use of information communication and sharing so as to accurately grasp the construction process; scientifically formulate plans; fundamentally solve the information fault between the stages of project planning, design, construction, and maintenance management; and realize the exchange, sharing and management of project information throughout the life cycle.

The simulation results affirm the importance of project legal person control behavior in the PMC project organizational management system. When the acceleration of project legal person free will is high, the degree of disorder within the group increases significantly, and the fragmentation phenomenon occurs; while when the acceleration of project legal person free will is reduced, the orderliness within the group increases. But too little acceleration of the project legal person's free will causes prolonged group stabilization time, which negatively affects project cost and 


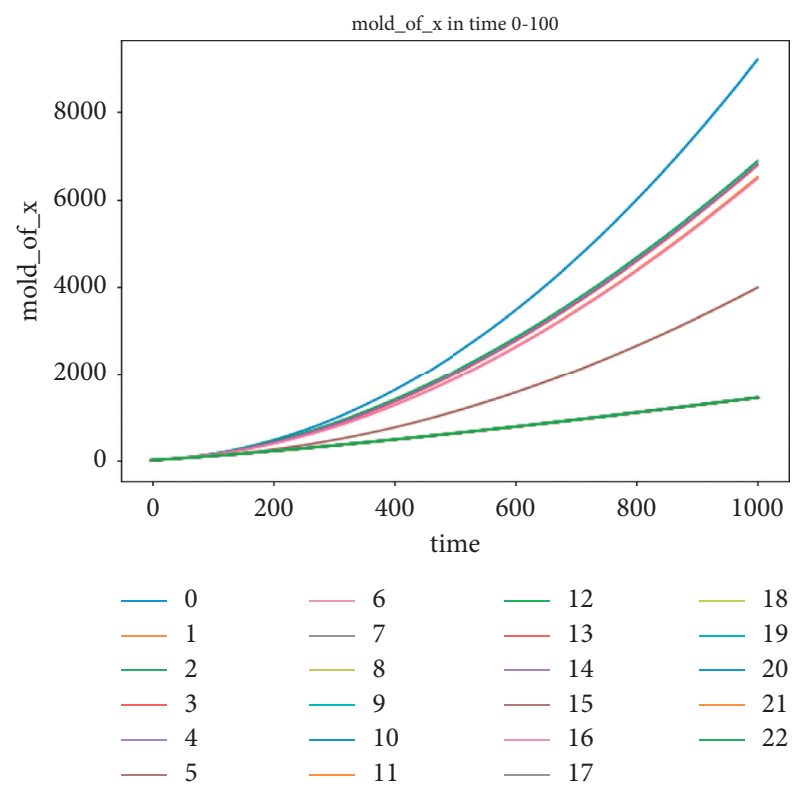

(a)

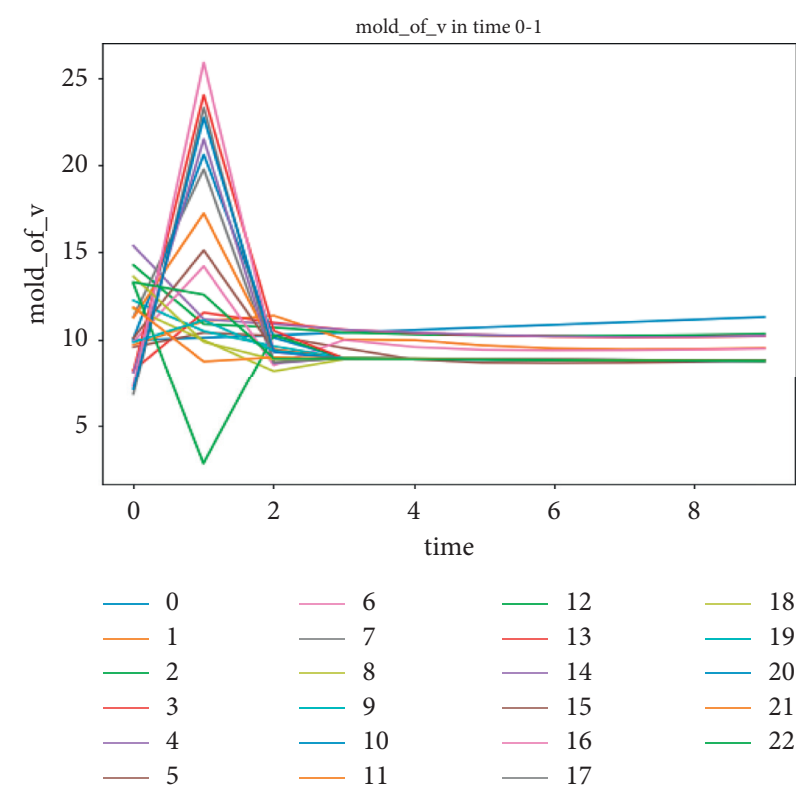

(b)

FIGURE 7: Evolution curve of location and velocity of M Project participants: (a) position evolution curve and (b) velocity evolution curve.

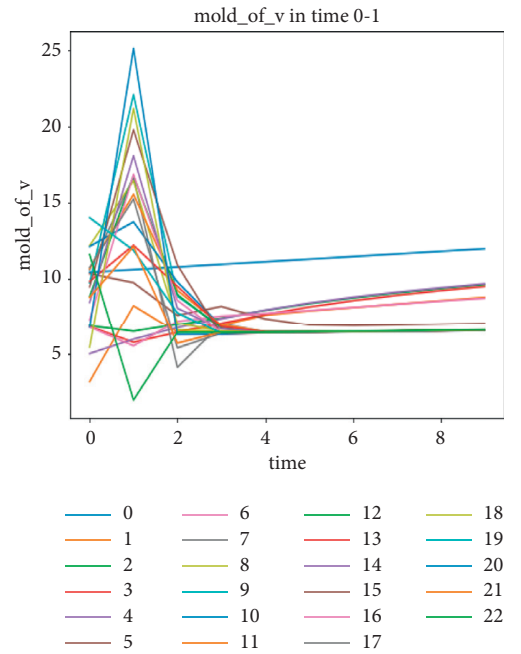

(a)
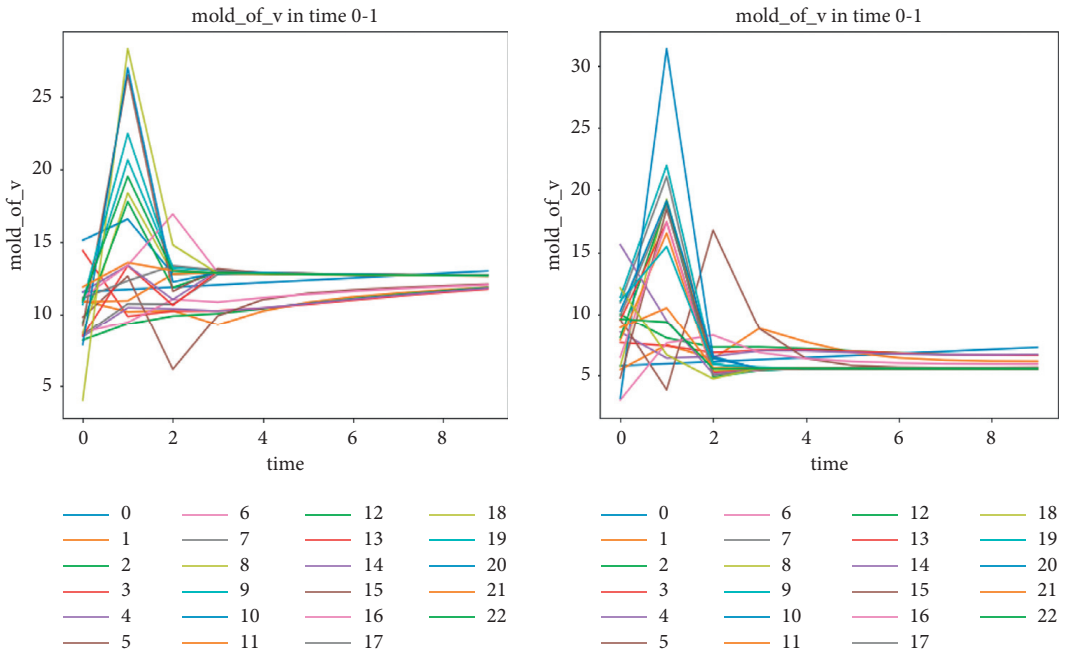

(b)

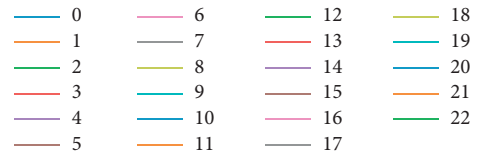

(c)

FIGURE 8: Velocity trajectory ( $\delta$ increases in turn).

schedule. Organizational behavior theory defines leadership as the ability to influence a group to achieve a vision or goal, in order to achieve the goal most effectively; organizations need strong leadership and effective management [60]. The traditional project construction mostly adopts the control model of "project legal person + supervision," in the face of large and complex projects; the project legal person mostly lacks professional knowledge and construction experience; and the supervision unit mainly provides consulting services for the project legal person, but in fact, the supervision unit in the current market does not have the ability to control and manage the whole project, and it is difficult to provide holistic and systematic advice to the project legal person. The
PMC contractor is large engineering management consulting enterprise with strong strength and rich engineering construction experience and professional staff, which can provide high-quality project management services for the project legal person in this project. Therefore, the project legal person should change the traditional concept, give up the specialized control work beyond the capacity, focus on strategic and macroscopic planning and control for the purpose of project goal achievement and sustainable development, and support PMC contractors in their work, which not only can enhance the control power of project progress but also can give full play to the management advantages of PMC contractor to organize and coordinate 

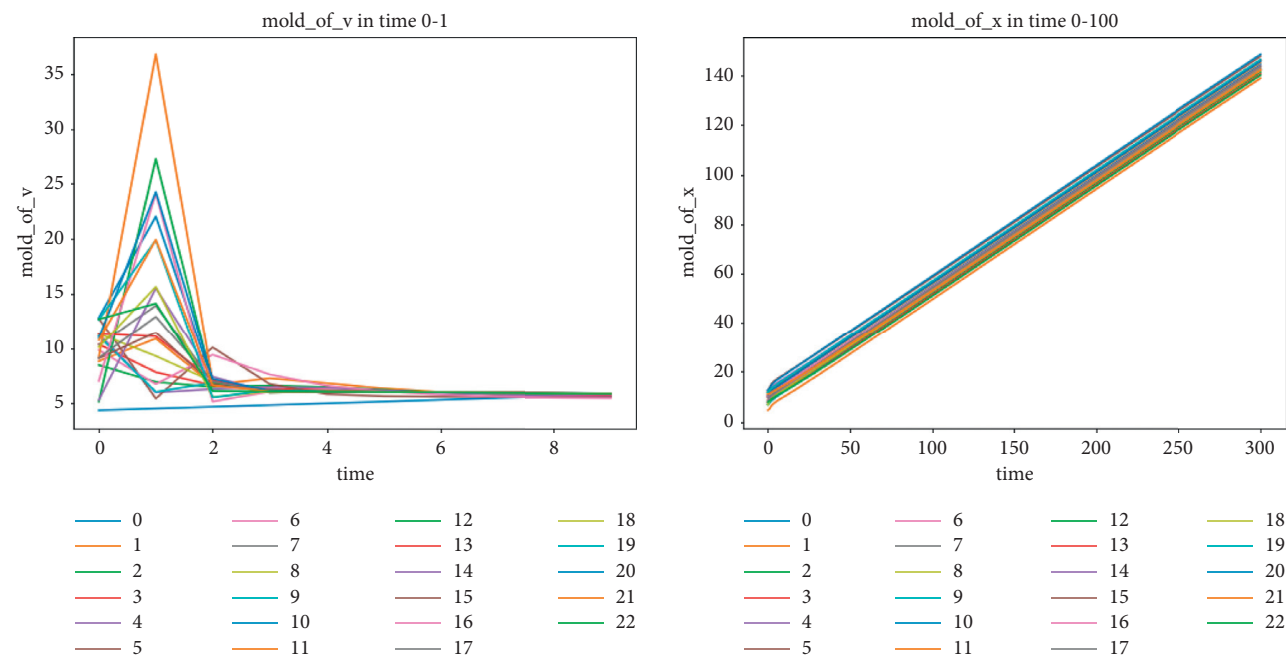

(a)
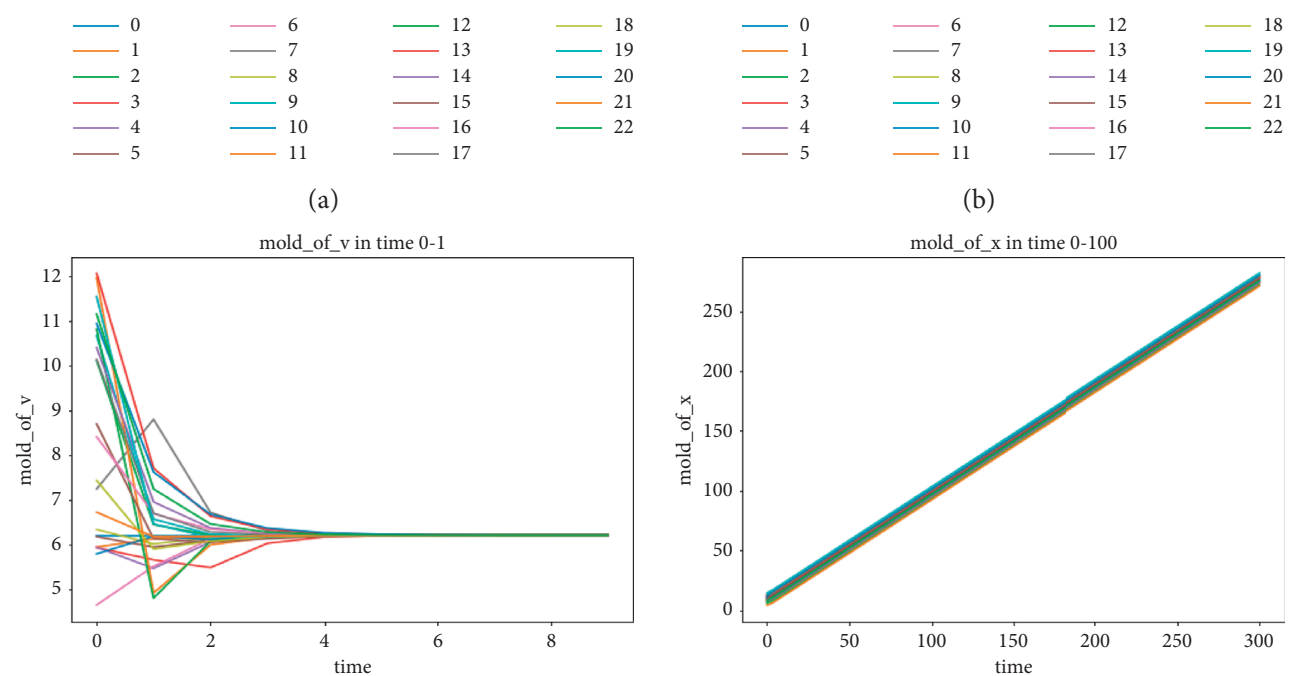

(b)
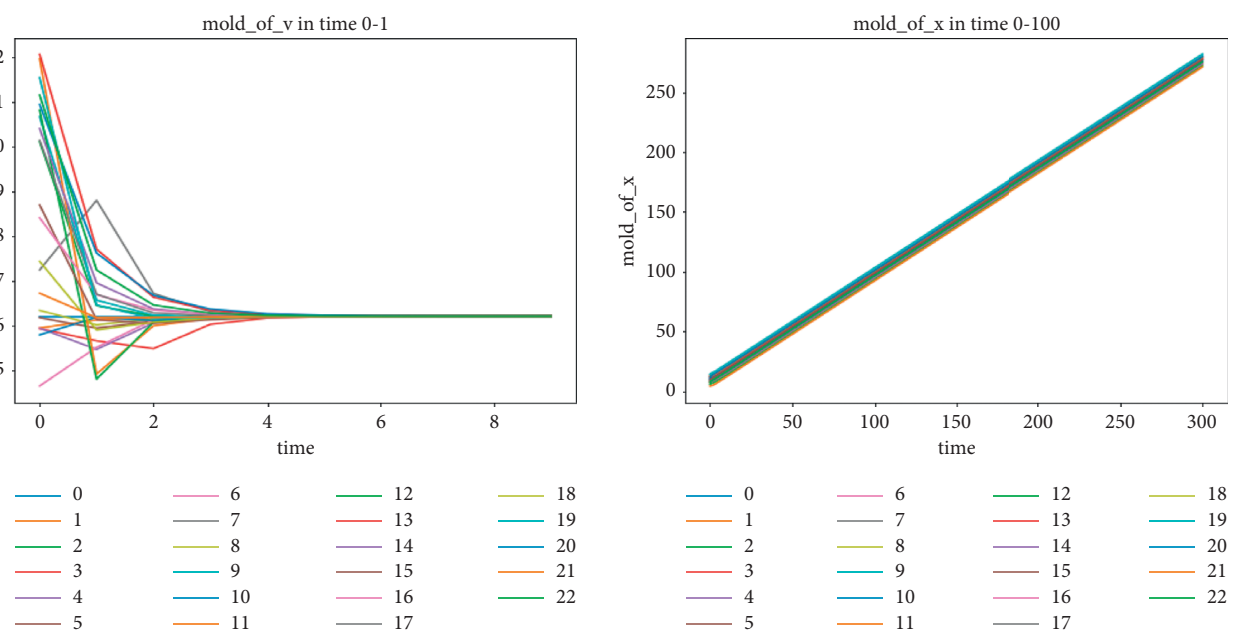

(c)

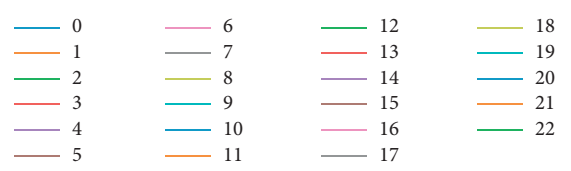

(d)
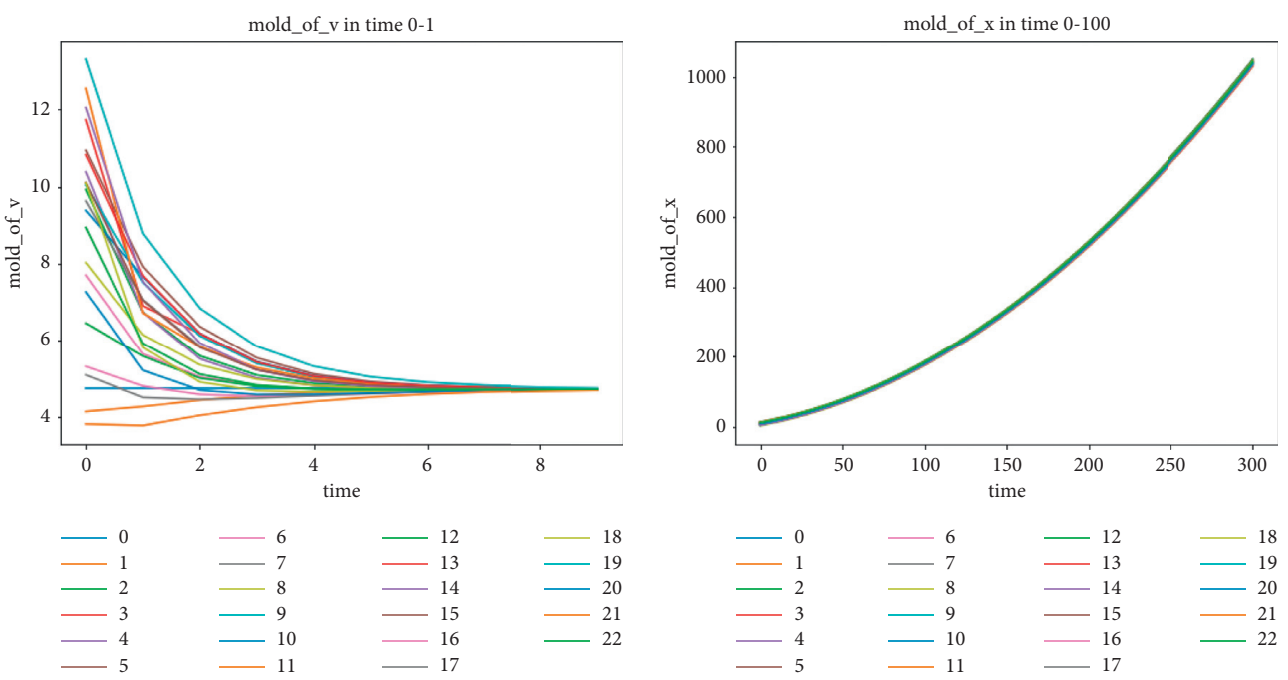

(e)

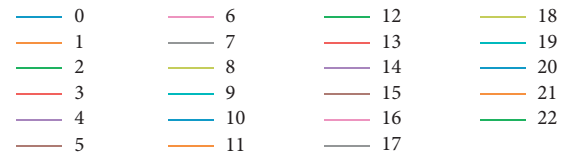

(f)

FIGURe 9: Evolution curve of position and velocity. 


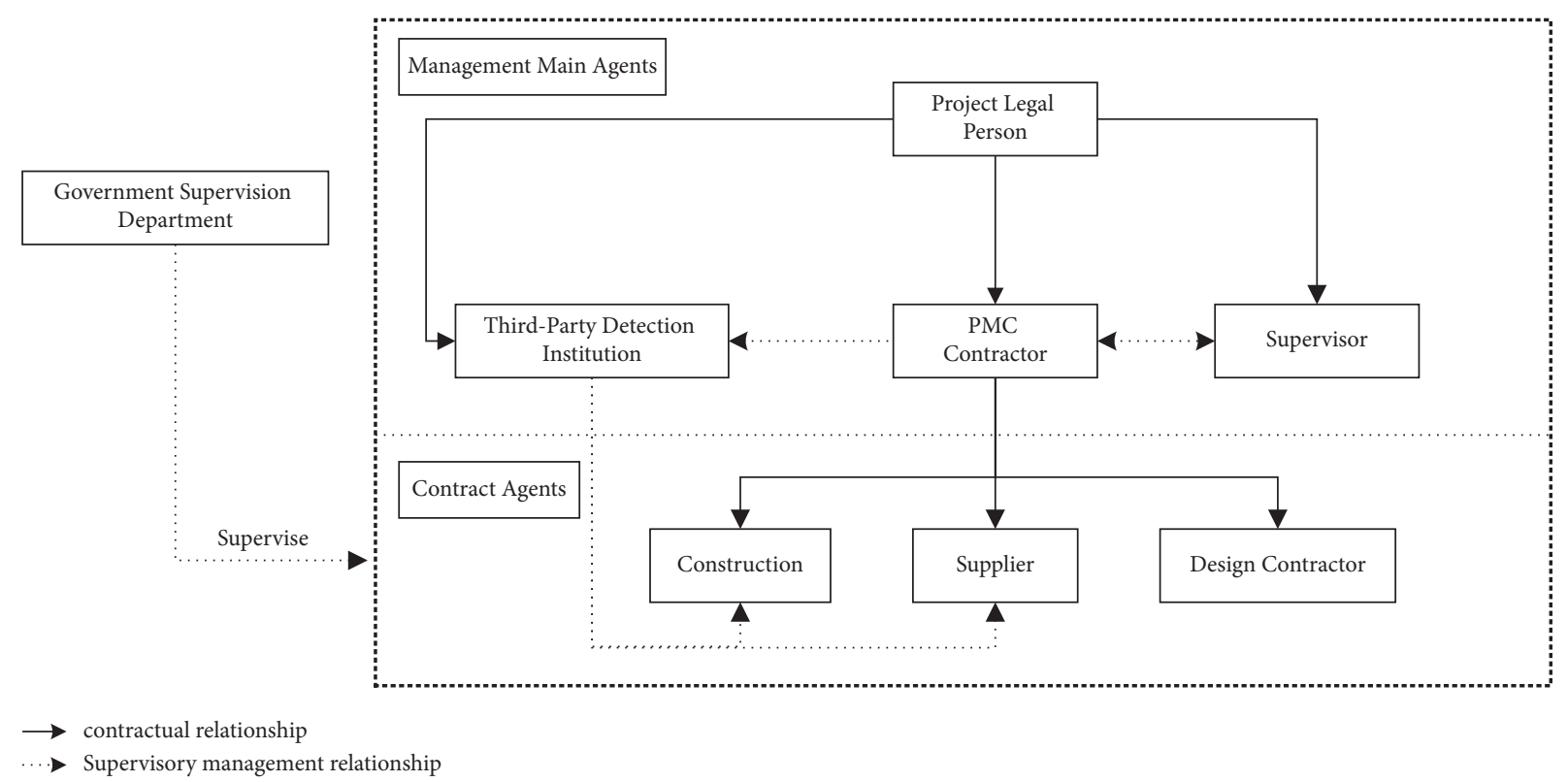

Figure 10: M Project management model after adjustment.

the specialized technical and construction forces in the market to cooperate with each other.

In summary, the main reasons for conflicts in the implementation of PMC projects in the Chinese context are the following three: (1) the lack of an intelligent information management platform, resulting in inefficient information communication; (2) the project legal person has too much control and tends to have a commanding leadership style, which hinders the development of the PMC contractor's management advantages; (3) the PMC project management system is too decentralized, resulting in inaccurate positioning and confusion in the scope of work of the project legal person, PMC contractor, designer and supervisor, and other major participants. In order to achieve synergy, the PMC project organizational management system must focus on breaking the institutional and conceptual barriers, strengthen the application of intelligent information technology, and construct a project management model with integrated control of the whole process by PMC contractors and effective macro supervision by the project legal person. With the gradual improvement of the construction level of fixed asset investment projects in China, when the project legal person does not have the ability to manage the project, the demand for comprehensive, cross-stage, and integrated consulting services is increasing in order to better achieve the investment purpose, and the contradiction between the real demand and the project management supply model caused by the current system is prominent. The management concept and method of the PMC model emphasizes integrated management, using systematic thinking to guide and manage practical activities, focusing on integrated management of the whole process, optimizing both design objectives and overall project benefits.

The simulation results show that to achieve synergy in the PMC model, first, to increase the PMC contractor's control over the project, the design side and supervision side into the PMC contractor's management scope so that it becomes the overall coordinator of the project, in order to facilitate the PMC contractor to carry out design optimization and control of each construction party, and second, the project legal person should reject the traditional project management concept, break the prejudice and distrust of PMC contractors, reduce the control of the project, and give full play to the professional and integrated management advantages of PMC contractors, while the project legal person is mainly responsible for efficient macro supervision and guiding the system to evolve in the direction favorable to the project objectives.

\section{Conclusion}

In order to overcome the management dilemma of antagonistic and conflict-ridden relationships between the participants within the organizational management system during the implementation of PMC projects in China, based on the idea of cluster dynamics, this paper used the Cucker-Smale mathematical model, introduced a hierarchy function in the model, and made the movement rules of the total leader have a free-will acceleration.

The results show that: (1) the role of mutual exchange of motor information among PMC project participants significantly influences the consistency of group motion and the matching of intragroup individual speed. When the weight of the role of mutual exchange of movement information between individuals increases, it contributes to the convergence of group movement while significantly contributing to the matching of intragroup individual speed. (2) The free will acceleration of the legal person can have an impact on the degree of intragroup disorder. Too large free will acceleration of the overall leader project legal person may increase the degree of intragroup disorder, which in turn leads to a larger speed matching difference and the 
emergence of subgroup aggregation, while too small may increase the group stability time, which has a negative impact on cost and schedule. (3) The implementation of PMC model needs to break the barriers of Chinese traditional project management concept and system; the project legal person should give up the management power beyond the capacity, include supervision and design into the management scope of PMC contractor, increase the actual control of PMC contractor to the project, and build the management system of integrated management of PMC contractor and macro supervision of project legal person, which can make the group move at the same speed and keep the cohesion; the organizational management system realize the orderly synergy; and the system forms a combined selforganized and other-organized control model.

In terms of the limitations of this study, first, the impact of the external environment on the project organizational management system is not considered, and second, the depth and scope of project management by the project legal person is not analyzed in detail. This kind of problem is worth further studying, and the subsequent study will introduce the effectiveness functions such as individual's perception ability of external environment and environmental noise impact, study the mechanism of the free will acceleration of project legal person on the system synergy in PMC model, and define its management depth and management scope quantitatively.

\section{Data Availability}

The data used to support the findings of this study are available from the corresponding author upon request.

\section{Conflicts of Interest}

The authors declare that they have no conflicts of interest.

\section{Acknowledgments}

This work was supported by the National Social Science Fund of P.R.C under Grant no. 17BGL156 and the Science and Technology Project Plan of Ministry of Housing and Urban Rural Development of the P.R.C under Grant no. 2018-K8-023.

\section{References}

[1] V. S. Anantatmula and P. F. Rad, "Role of organizational project management maturity factors on project success," Engineering Management Journal, vol. 30, no. 3, pp. 165-178, 2018.

[2] H. Abdirad, C. S. Dossick, B. R. Johnson, and G. Migliaccio, "Disruptive information exchange requirements in construction projects: perception and response patterns," Building Research \& Information, vol. 49, no. 2, pp. 161-178, 2021.

[3] N. Zhao and S. An, "Collaborative management of complex major construction projects: AnyLogic-based simulation modelling," Discrete Dynamics in Nature and Society, vol. 2016, Article ID 6195673, 8 pages, 2016.
[4] S. Luo, P. Cheng, J. Wang, and Y. Huang, "Selecting project delivery systems based on simplified neutrosophic linguistic preference relations," Symmetry, vol. 9, no. 8, p. 151, 2017.

[5] R. Ruparathna and K. Hewage, "Review of contemporary construction procurement practices," Journal of Management in Engineering, vol. 31, no. 3, Article ID 04014038, 2015.

[6] D. Ciric, M. Delic, B. Lalic, D. Gracanin, and T. Lolic, "Exploring the link between project management approach and project success dimensions: a structural model approach," Advances in Production Engineering \& Management, vol. 16, no. 1, pp. 99-111, 2021.

[7] Y. Huang and S. Pan, "Risk prevention strategy of international engineering project under PMC management mode," SME Management and Technology, vol. 21, pp. 48-50, 2021, in Chinese.

[8] Y. H. Kwak, H. Sadatsafavi, J. Walewski, and N. L. Williams, "Evolution of project based organization: a case study," International Journal of Project Management, vol. 33, no. 8, pp. 1652-1664, 2015.

[9] B. Lee, L. Changjun, and H. S. Heon, "International PMC project competency enhancement strategies for domestic engineering companies," Journal of the Korean Society of Civil Engineers, vol. 38, no. 1, pp. 121-132, 2018.

[10] T. Huang and L. Cao, "Discussion on schedule and plan management under PMC mode," Value Engineering, vol. 38, no. 8, pp. 75-77, 2019, in Chinese.

[11] D. Q. Tran and K. R. Molenaar, "Risk-based project delivery selection model for highway design and construction," Journal of Construction Engineering and Management, vol. 141, no. 12, Article ID 04015041, 2015.

[12] G. M. Winch, "Three domains of project organising," International Journal of Project Management, vol. 32, no. 5, pp. 721-731, 2014.

[13] M. Sanchez-Silva, "Managing infrastructure systems through changeability," Journal of Infrastructure Systems, vol. 25, no. 1, Article ID 04018040, 2019.

[14] M. Parchami Jalal and S. Matin Koosha, "Identifying organizational variables affecting project management office characteristics and analyzing their correlations in the Iranian project-oriented organizations of the construction industry," International Journal of Project Management, vol. 33, no. 2, pp. 458-466, 2015.

[15] P. Jafari, E. Mohamed, S. Lee, and S. Abourizk, "Social network analysis of change management processes for communication assessment," Automation in Construction, vol. 118, Article ID 103292, 2020.

[16] S. Z. Dogan, D. Arditi, S. Gunhan, and B. Erbasaranoglu, "Assessing coordination performance based on centrality in an E-mail communication network," Journal of Management in Engineering, vol. 31, no. 3, Article ID 04014047, 2015.

[17] D. Zhao, M. Duva, S. Mollaoglu, K. Frank, A. Garcia, and J. Tait, "Integrative collaboration in fragmented project organizations: network perspective," Journal of Construction Engineering and Management, vol. 147, no. 10, Article ID 04021115, 2021.

[18] J. Xue, G. Q. P. Shen, R. J. Yang, I. Zafar, and E. M. A. C. Ekanayake, "Dynamic network analysis of stakeholder conflicts in megaprojects: sixteen-year case of Hong Kong-Zhuhai-Macao bridge," Journal of Construction Engineering and Management, vol. 146, no. 9, Article ID 04020103, 2020.

[19] A. Singh and H. M. Johnson, "Peer-reviewed paper: conflict management diagnosis at project management 
organizations," Journal of Management in Engineering, vol. 14, no. 5, pp. 48-63, 1998.

[20] I. U. Altuncan and A. M. Tanyer, "Context-dependent construction conflict management performance analysis based on competency theory," Journal of Construction Engineering and Management, vol. 144, no. 12, Article ID 04018112, 2018.

[21] A. A. Tabassi, A. Abdullah, and D. J. Bryde, "Conflict management, team coordination, and performance within multicultural temporary projects: evidence from the construction industry," Project Management Journal, vol. 50, no. 1, pp. 101-114, 2019.

[22] D. Özdemir Güngör and S. Gözlü, "An analysis of the links between project success factors and project performance," Sigma Journal of Engineering and Natural Sciences, vol. 34, no. 2, pp. 223-239, 2016.

[23] C. Lee, J. W. Won, W. Jang, W. Jung, S. H. Han, and Y. H. Kwak, "Social conflict management framework for project viability: case studies from Korean megaprojects," International Journal of Project Management, vol. 35, no. 8, pp. 1683-1696, 2017.

[24] N. Wang, M. Ma, G. Wu, Y. Liu, Z. Gong, and X. Chen, "Conflicts concerning construction projects under the challenge of cleaner production-case study on government funded projects," Journal of Cleaner Production, vol. 225, pp. 664-674, 2019.

[25] F. W. Zhu, L. Z. Wang, M. Yu, and X. T. Yang, "Quality of conflict management in construction project context conceptualization, scale development, and validation," Engineering Construction and Architectural Management, vol. 27, no. 5, pp. 1191-1211, 2020.

[26] Y. Li, Y. Lu, J. E. Taylor, and Y. Han, "Bibliographic and comparative analyses to explore emerging classic texts in megaproject management," International Journal of Project Management, vol. 36, no. 2, pp. 342-361, 2018.

[27] J. Pollack, C. Biesenthal, S. Sankaran, and S. Clegg, "Classics in megaproject management: a structured analysis of three major works," International Journal of Project Management, vol. 36, no. 2, pp. 372-384, 2018.

[28] X. Qian, G. Xu, and S. Wang, Technology of Organizational Management - Systems Engineering (On Systems Engineering Revised Edition), Hunan Science and Technology Press, Changsha, China, 1988, in Chinese.

[29] R. Yin, Y. Wang, and B. Li, Engineering Philosophy, Higher Education Press, Beijing, China, 2018, in Chinese.

[30] A. Ceric, M. Vukomanovic, I. Ivic, and S. Kolaric, "Trust in megaprojects: a comprehensive literature review of research trends," International Journal of Project Management, vol. 39, no. 4, pp. 325-338, 2021.

[31] Q. Li, Z. M. Yin, H. Y. Chong, and Q. Shi, "Nexus of interorganizational trust, principled negotiation, and joint action for improved cost performance: survey of Chinese megaprojects," Journal of Management in Engineering, vol. 34, no. 6, Article ID 04018036, 2018.

[32] M. Miterev, J. R. Turner, and M. Mancini, “The organization design perspective on the project-based organization: a structured review," International Journal of Managing Projects in Business, vol. 10, no. 3, pp. 527-549, 2017.

[33] S. Ha, D. Ko, and Y. Zhang, "Critical coupling strength of the Cucker-Smale model for flocking," Mathematical Models and Methods in Applied Sciences, vol. 27, no. 6, pp. 1051-1087, 2017.

[34] T. Vicsek, A. Czirók, E. Ben-Jacob, I. Cohen, and O. Shochet, "Novel type of phase transition in a system of self-driven particles," Physical Review Letters, vol. 75, no. 6, pp. 1226-1229, 1995.

[35] A. Jadbabaie, J. Jie Lin, and A. S. Morse, "Coordination of groups of mobile autonomous agents using nearest neighbor rules," IEEE Transactions on Automatic Control, vol. 48, no. 6 , pp. 988-1001, 2003.

[36] F. Cucker and S. Smale, "Emergent behavior in flocks," IEEE Transactions on Automatic Control, vol. 52, no. 5, pp. 852862, 2007.

[37] F. Cucker and S. Smale, "On the mathematics of emergence," Japanese Journal of Mathematics, vol. 2, no. 1, pp. 197-227, 2007.

[38] J. Shen, "Cucker-smale flocking under hierarchical leadership," SIAM Journal on Applied Mathematics, vol. 68, no. 3, pp. 694-719, 2008.

[39] F. Cucker and J.-G. Dong, "On the critical exponent for flocks under hierarchical leadership," Mathematical Models and Methods in Applied Sciences, vol. 19, no. 1, pp. 1391-1404, 2009.

[40] F. Cucker and E. Mordecki, "Flocking in noisy environments," Journal de Mathematiques Pures et Appliquees, vol. 89, no. 3, pp. 278-296, 2008.

[41] R. Erban, J. Haškovec, and Y. Sun, "A cucker-smale model with noise and delay," SIAM Journal on Applied Mathematics, vol. 76, no. 4, pp. 1535-1557, 2016.

[42] J. G. Dong, S. Y. Ha, and D. Kim, "Interplay of time-delay and velocity alignment in the Cucker-Smale model on a general diagraph," Discrete Cont Dyn-B, vol. 24, pp. 5569-5600, 2018.

[43] F. Cucker and J. G. Dong, "A conditional, collision-avoiding model for swarming," Discrete \& Continuous Dynamical Systems, vol. 34, no. 3, pp. 1009-1020, 2014.

[44] I. Markon, "Collision-avoiding in the singular Cucker-Smale model with nonlinear velocity couplings," Discrete \& Continuous Dynamical Systems, vol. 38, no. 10, pp. 5245-5260, 2018.

[45] X. Yin, D. Yue, and Z. Chen, "Asymptotic behavior and collision avoidance in the Cucker-Smale model," IEEE Transactions on Automatic Control, vol. 65, no. 7, pp. 31123119, 2020.

[46] F. Cucker and J.-G. Dong, "On flocks influenced by closest neighbors," Mathematical Models and Methods in Applied Sciences, vol. 26, no. 14, pp. 2685-2708, 2016.

[47] C. Pignotti and I. Reche Vallejo, "Flocking estimates for the Cucker-Smale model with time lag and hierarchical leadership," Journal of Mathematical Analysis and Applications, vol. 464, no. 2, pp. 1313-1332, 2018.

[48] F. Paita, G. Gomez, and J. J. Masdemont, "On the CuckerSmale flocking model applied to a formation moving in a central force field," Marine Ecology Progress, vol. 386, pp. 181-195, 2013.

[49] A. Belkadi, Z. Liu, L. Ciarletta, Y. Zhang, and D. Theilliol, "Flocking control of a fleet of unmanned aerial vehicles," Control Theory and Technology, vol. 16, no. 2, pp. 82-92, 2018.

[50] H. O. Bae, S. Y. Ha, Y. Kim, S. H. Lee, H. Lim, and J. Yoo, “A mathematical model for volatility flocking with a regime switching mechanism in a stock market," Mathematical Models and Methods in Applied Sciences, vol. 25, no. 7, pp. 1299-1335, 2015.

[51] S. Cheng, "Complex science and systems engineering," Journal of Management Science, vol. 2, pp. 3-9, 1999, in Chinese.

[52] T. Castillo, L. F. Alarcón, and E. Pellicer, "Influence of organizational characteristics on construction project performance using corporate social networks," Journal of 
Management in Engineering, vol. 34, no. 4, Article ID 04018013, 2018.

[53] T. Wang, W. Tang, D. Qi, W. Shen, and M. Huang, "Enhancing design management by partnering in delivery of international EPC projects: evidence from Chinese construction companies," Journal of Construction Engineering and Management, vol. 142, no. 4, Article ID 04015099, 2016.

[54] W. Shen, B. Choi, S. Lee, W. Tang, and C. T. Haas, "How to improve interface management behaviors in EPC projects: roles of formal practices and social norms," Journal of Management in Engineering, vol. 34, no. 6, Article ID 04018032, 2018.

[55] D. Cao, H. Li, G. Wang, X. Luo, X. Yang, and D. Tan, "Dynamics of project-based collaborative networks for BIM implementation: analysis based on stochastic actor-oriented models," Journal of Management in Engineering, vol. 33, no. 3, Article ID 04016055, 2017.

[56] A. Ospina-Alvarado, D. Castro-Lacouture, and J. S. Roberts, "unified framework for construction project integration," Journal of Construction Engineering and Management, vol. 142, no. 7, Article ID 04016019, 2016.

[57] A. S. Hanna, "Benchmark performance metrics for integrated project delivery," Journal of Construction Engineering and Management, vol. 142, no. 9, 2016.

[58] D. Grau, W. E. Back, and G. Mejia-Aguilar, "Organizationalbehavior influence on cost and schedule predictability," Journal of Management in Engineering, vol. 33, no. 5, Article ID 04017027, 2017.

[59] H. Guo, R. Yu, and Y. Fang, "Analysis of negative impacts of BIM-enabled information transparency on contractors' interests," Automation in Construction, vol. 103, pp. 67-79, 2019.

[60] S. P. Robbins and T. A. Judge, Organizational Behavior, Pearson, London, UK, 2019. 